\title{
On multiple-nutrient-limited growth of microorganisms, with special reference to dual limitation by carbon and nitrogen substrates
}

\author{
Thomas Egli \\ Swiss Federal Institute for Water Resources and Water Pollution Control (EAWAG), Überlandstrasse 133, \\ CH-8600 Dübendorf, Switzerland
}

Key words: chemostat, growth yield, growth limitation, multiple nutrient limitation, carbon, nitrogen

\begin{abstract}
Simultaneous limitation of microbial growth by two or more nutrients is discussed for dual carbon/nitrogenlimited growth in continuous culture. The boundaries of the zone where double-limited growth occurs can be clearly defined from both cultivation data and cellular composition and they can be also predicted from growth yield data measured under single-substrate-limited conditions. It is demonstrated that for the two nutrients carbon and nitrogen the zone of double nutrient limitation is dependent on both the $\mathrm{C}: \mathrm{N}$ ratio of the growth medium and the growth (dilution) rate. The concept on double-(carbon/nitrogen)-limited growth presented here can be extended to other binary and multiple combinations of nutrients.
\end{abstract}

\section{Introduction}

The use of defined mineral media for the growth of microorganisms was a major development in microbiology. In combination with advances in cultivation techniques, e.g. the chemostat culture, it enabled the reproducible growth of microbes in selected environments under defined conditions and to study the effects of specific nutrients on various physiological phenomena. As a general rule, defined mineral media have been formulated so as to allow microbes to synthesize their cellular components from single sources of carbon, nitrogen, phosphorus, etc. Additionally, it became common practice for the relative concentrations of the individual nutrients to be adjusted such that, as formulated in the 'Law of the minimum' by Justus von Liebig (1840), only one of them, usually the carbon source, restricted the maximum quantity of biomass that could be produced, with all other nutrients in excess (Monod 1942; Stephenson 1949).
In contrast to the conditions which microbes are exposed to in laboratory cultures, the environments encountered in Nature are entirely different. There, microbes have to cope with both the simultaneous presence and low concentrations of a multiplicity of homologous nutrients, i.e., compounds that can satisfy the same physiological function. This is especially true for carbon, nitrogen and phosphorus sources. In fact, it has been pointed out that the presumption that limitation of growth in Nature is limited by either a single substrate or nutrient is probably an erroneous assumption (Veldkamp \& Jannasch 1972; Pearl 1977). Although, considerable progress has been made in recent years with respect to understanding the simultaneous growth on either two carbon sources or two electron acceptors (Harder \& Dijkhuizen 1976; Harder \& Dijkhuizen 1982; Egli et al. 1986; Robertson \& Kuenen 1990), there have been few reports concerning the simultaneous limitation by multiple non-homologous nutrients, as discussed by Harrison (1972) and Baltzis \& Fredrickson 
(1988). Consequently, most microbiologists still support the view that only one compound can be growth-limiting at any particular time.

In this contribution evidence supporting the existence of well-defined multiple-substrate-limited growth regimes will be evaluated. Due to the paucity of data, examples of the simultaneous limitation of growth by two macro-nutrients, carbon and nitrogen, will be emphasized, but it will become clear that the principle of multiple-nutrient-limited growth is equally applicable to a wide range of other nutrient limitations. The influence that simultaneous growth limitation by carbon and nitrogen has on cell composition and cell physiology will be examined and a working hypothesis for multiple-nutrient-limited growth of microbes will be presented.

\section{The phenomenon of multiple-nutrient-limited growth}

First hints that growth of phytoplankton may be limited by several factors simultaneously were reported for oligotrophic freshwater systems (summarized in Pearl 1977). With respect to microorganisms, preliminary experimental data suggesting the occurrence of simultaneous limitation of growth by two heterologous nutrients was reported by Cooney et al. (1976) for nitrogen and phosphorus, Hueting \& Tempest (1979) for carbon and nitrogen and for carbon and potassium, Harrison (1972) and Hamer et al. (1975) for gaseous nutrients, and by Egli (1982) for carbon and nitrogen. However, it was only recently, that the existence of a double carbon/nitrogen-limited growth regime under chemostat culture conditions was clearly demonstrated for both bacteria and yeast on the basis of both the culture parameters and the physiological characteristics of the growing cells (Egli \& Quayle 1984; Egli \& Quayle 1986; Gräzer-Lampert et al. 1986; Minkevich et al. 1988; Duchars \& Attwood 1989; Rutgers et al. 1990).

A typical example for the response generally observed as a function of the $\mathrm{C}: \mathrm{N}$ ratio in the feed medium is illustrated in Fig. 1 for a culture of Hyphomicrobium ZV620 growing at a constant di- lution rate of $0.054 \mathrm{~h}^{-1}$ in a chemostat with methanol $/ \mathrm{NH}_{4}{ }^{+}$as the carbon/nitrogen sources. In this experiment the concentration of the nitrogen source $\left(\mathrm{NH}_{4}^{+}\right)$in the medium reservoir was kept constant at $223 \mathrm{mg} \mathrm{l}^{-1} \mathrm{NH}^{4}{ }_{+}-\mathrm{N}$, whilst the concentration of methanol was increased stepwise from $0.95 \mathrm{~g} \mathrm{l}^{-1}(\mathrm{C}: \mathrm{N}=1.6)$ to $12.4 \mathrm{~g} \mathrm{l}^{-1}(\mathrm{C}: \mathrm{N}=$ 20.85). Judging from the residual concentrations of methanol and $\mathrm{NH}_{4}{ }^{+}$, the cellular composition and the synthesis of $\mathrm{NH}_{4}{ }^{+}$-assimilating enzymes, three distinct growth regimes were recognized:

- methanol limitation where ammonia was in excess $(\mathrm{C}: \mathrm{N}<7.1)$

- ammonia limitation were methanol was in excess $(C: N>12.6)$

- a transition regime where both methanol and $\mathrm{NH}_{4}{ }^{+}$were below the detection limit $(7.1<\mathrm{C}: \mathrm{N}<12.6)$

It is striking that, although apparently growing nitrogen-limited at $\mathrm{C}: \mathrm{N}>7.1$, where no residual nitrogen was detectable, the dry weight of the culture still increased linearly when additional carbon substrate was added to the growth medium (Fig. 1A). When growth was limited by a single nutrient only, the cells exhibited essentially a constant overall cellular composition with respect to $\mathrm{N}$, protein and storage product contents (Fig. 1B). Within the transition growth regime cell composition was extremely dependent on the ratio of the two limiting substrates and it was adjusted according to the actual availability of the two nutrients which restricted the synthesis of cell material. It was calculated that the storage material poly- $\beta$-hydroxybutyrate (PHB) synthesized under these conditions accounted for up to $90 \%$ of the additional biomass produced (Gräzer-Lampert et al. 1986). Generalizing, one can conclude from the data that during carbon-limited growth, the content of protein and probably also of nucleic acids is high and the storage product content is low, whereas the opposite is true for cells grown under nitrogen limitation. This finding is not new and has been reported for many microbes although, as far as the author is aware, overall cell composition was always implied rather 


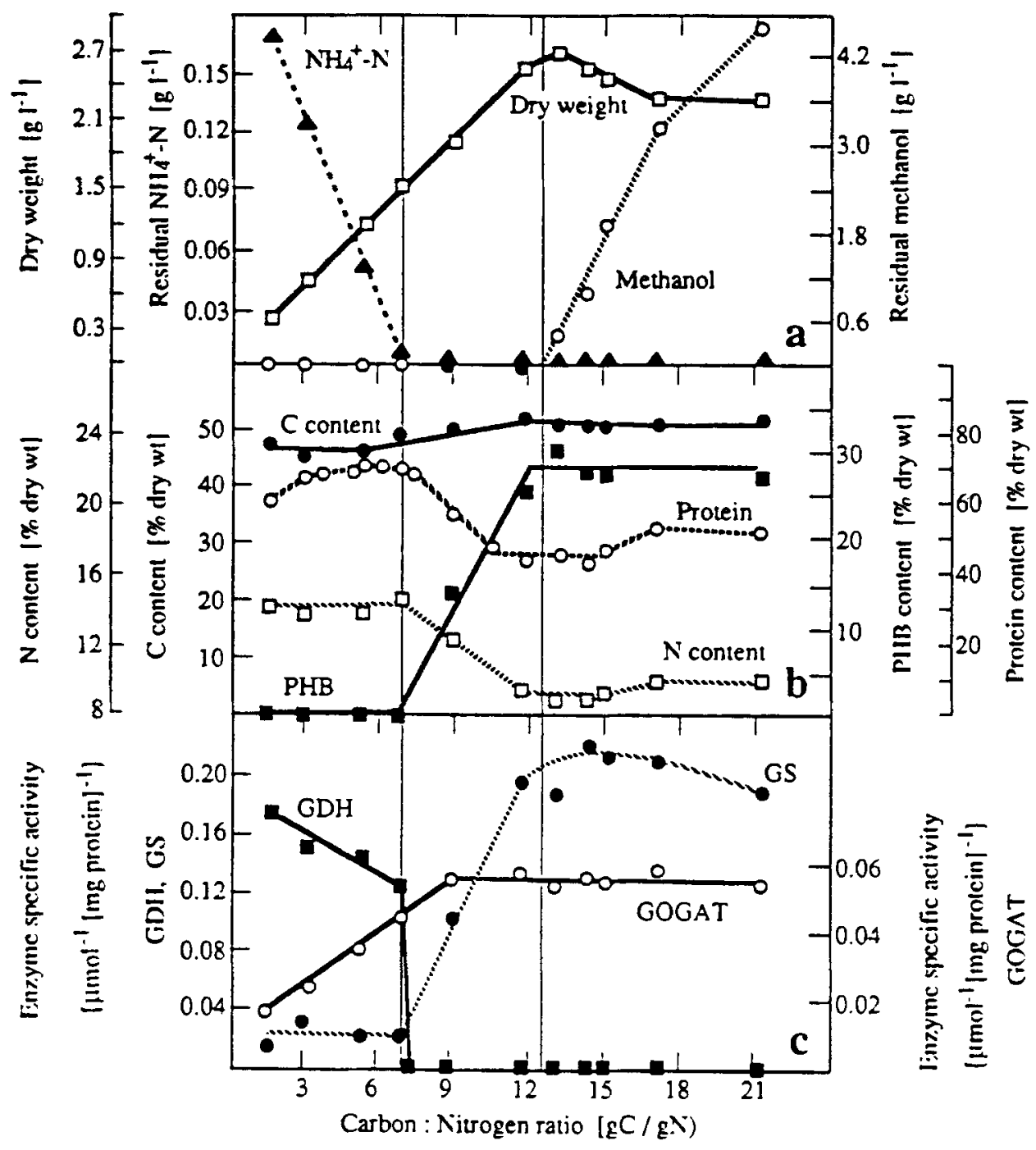

Fig. 1. Cellular and enzymatic composition of Hyphomicrobium ZV620 grown with methanol and $\mathrm{NH}_{4}{ }^{+}$in a chemostat at a constant dilution rate, $\mathrm{D}=0.054 \mathrm{~h}^{-1}$, as a function of the carbon : nitrogen ratio in the feed $\left[\mathrm{S}_{6}\left(\mathrm{NH}_{4}{ }^{+}-\mathrm{N}\right)\right.$ was held constant, $\mathrm{S}_{0}(\mathrm{methanol})$ was increased]. Abbreviations: GS, glutamine synthetase, GOGAT, glutamate synthase; GDH, glutamate dehydrogenase; PHB, poly- $\beta$ hydroxybutyrate. Data from Gräzer-Lampert et al. (1986).

than shown to be independent of the medium $\mathrm{C}: \mathrm{N}$ ratio.

As a response to the growth conditions described above, the protein composition of cells of $\mathrm{Hy}$ phomicrobium ZV620 was not only affected quantitatively, but also qualitatively. The data in Fig. 1C demonstrate that in this bacterium, ammonia was assimilated mainly via the low affinity glutamate dehydrogenase system under nitrogen excess growth conditions, whereas, as soon as the availability of ammonia became restricted, the high af- finity glutamine synthetase/glutamate synthase system took over. It was surprising to see how differently synthesis of the three enzymes involved was regulated. Gräzer-Lampert et al. (1986) also showed that not only the concentration of the total glutamine synthetase protein increased during the change from $\mathrm{C}$ - to $\mathrm{N}$-limited conditions, but also the fraction of deadenylated, i.e., active glutamine synthetase increased.

A very similar behaviour with respect to cell composition and enzyme regulation has been re- 
ported for the methylotrophic yeast Hansenula polymorpha during chemostat growth at a constant dilution rate of $0.10 \mathrm{~h}^{-1}$ with media containing different $\mathrm{C}: \mathrm{N}$ ratios, where a $\mathrm{C} / \mathrm{N}$-limited transition growth regime was observed between $12<\mathrm{C}: \mathrm{N}<$ 31 (Egli \& Quayle 1986). Recently, Minkevich et al. (1988), using the same experimental approach, reported the existence of a double carbon/nitrogen-limited growth regime for the yeast Candida valida, Duchars \& Attwood (1989) for Hyphomicrobium X, Al-Awadhi et al. (1990) for the growth of a thermotolerant methylotrophic Bacillus sp., and Rutgers et al. (1990) for Klebsiella pneumoniae. All these authors observed a virtually identical pattern of behaviour for the cellular composition of these organisms as that described above for Hyphomicrobium. From all this experimental evidence for different microorganisms, one can conclude that the existence of a transition, i.e., a double-substrate-limited, growth regime between two distinct single-nutrient-limited zones for growth is a general phenomenon.

\section{Prediction of range of double-substrate-limited growth}

Accepting the existence of the phenomenon prompts the question of whether the range where growth is limited by restrictions in the availability of two (or more) nutrients simultaneously can be predicted. From their experimental data, Egli \& Quayle (1986) demonstrated that the bounderies of the three growth regimes at a certain fixed growth rate could be predicted when the growth yields for the individual substrates are known.

The empirical equation for the concentration of biomass in the culture ( $\mathrm{x}$ ), as first proposed by Egli $\&$ Quayle (1986) for the two nutrients carbon and nitrogen, can be deduced from the conceptual scheme shown in Fig. 2, i.e.,

$$
\mathrm{x}=\left(\mathrm{c}_{0}-\mathrm{c}\right) \cdot \mathrm{Y}_{\mathrm{X} / \mathrm{C}}=\left(\mathrm{n}_{0}-\mathrm{n}\right) \cdot \mathrm{Y}_{\mathrm{X} / \mathrm{N}}
$$

where $c_{0}$ and $\mathbf{n}_{0}$ are the concentrations of carbon and nitrogen in the chemostat feed, $c$ and $n$ are the corresponding residual concentrations of the two

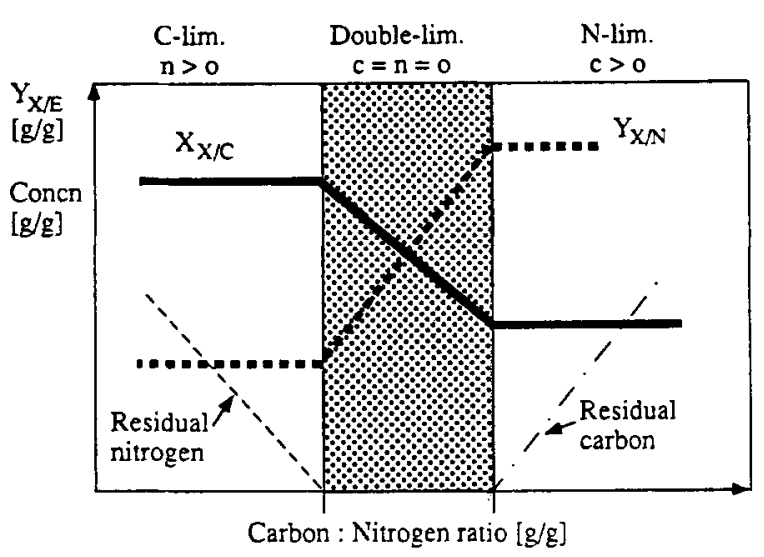

Fig. 2. Conceptual diagram showing the dependence of the growth yield for carbon $\left(\mathrm{Y}_{\mathrm{X} / \mathrm{C}}\right)$ and nitrogen $\left(\mathrm{Y}_{\mathrm{X} / \mathrm{N}}\right)$ on the carbon: nitrogen ratio in the growth medium supplied. It is assumed that growth takes place in a chemostat at a constant dilution rate. The residual concentrations of the carbon (c) and the nitrogen (n) source, respectively, in the culture are shown. The yield is given as dry biomass formed per g of element $\left(\mathrm{Y}_{\mathrm{XE}}\right)$.

nutrients and $\mathrm{Y}_{\mathrm{X} / \mathrm{C}}$ and $\mathrm{Y}_{\mathrm{X} / \mathrm{N}}$ are the biomass growth yield coefficients based on carbon and nitrogen. Because both $\mathrm{c}$ and $\mathrm{n}$ approach zero under carbon/ nitrogen-limited growth, equation (1) can be rewritten in terms of the $C: N$ ratio in the inflowing medium, i.e.,

$$
\mathrm{c}_{0} / \mathrm{n}_{0}=\mathrm{Y}_{\mathrm{X} / \mathrm{N}} / \mathrm{Y}_{\mathrm{X} / \mathrm{C}}
$$

Assuming constant yield coefficients under singlesubstrate-limited growth conditions, the boundary between carbon limitation and carbon/nitrogen limitation can be calculated by substituting values for $\mathrm{Y}_{\mathrm{X} / \mathrm{N}}$ and $\mathrm{Y}_{\mathrm{X} / \mathrm{C}}$ values measured under carbonlimited growth conditions into equation (2). Similarly, substituting $\mathrm{Y}_{\mathrm{X} / \mathrm{N}}$ and $\mathrm{Y}_{\mathrm{X} / \mathrm{C}}$ measured for nitro-

Table 1. Predicted and experimentally observed boundaries for single and double-substrate(carbon/nitrogen)-limited growth of Hyphomicrobium $\mathrm{ZV} 620$ with methanol and $\mathrm{NH}_{4}{ }^{+}$at a constant dilution rate of $0.054 \mathrm{~h}^{-1}$ in the chemostat.

\begin{tabular}{lcrcc}
\hline & $\mathrm{Y}_{\mathrm{X} / \mathrm{C}}$ & $\mathrm{Y}_{\mathrm{X} / \mathrm{N}}$ & $\begin{array}{l}\mathrm{C}: \mathrm{N} \\
\text { predicted }\end{array}$ & $\begin{array}{l}\mathrm{C}: \mathrm{N} \\
\text { observed }\end{array}$ \\
\hline C-limited & 0.99 & 7.19 & 7.2 & 7.1 \\
N-limited & 0.80 & 10.30 & 12.8 & 12.6 \\
\hline
\end{tabular}

Experimental data from Gräzer-Lampert et al. (1986). 


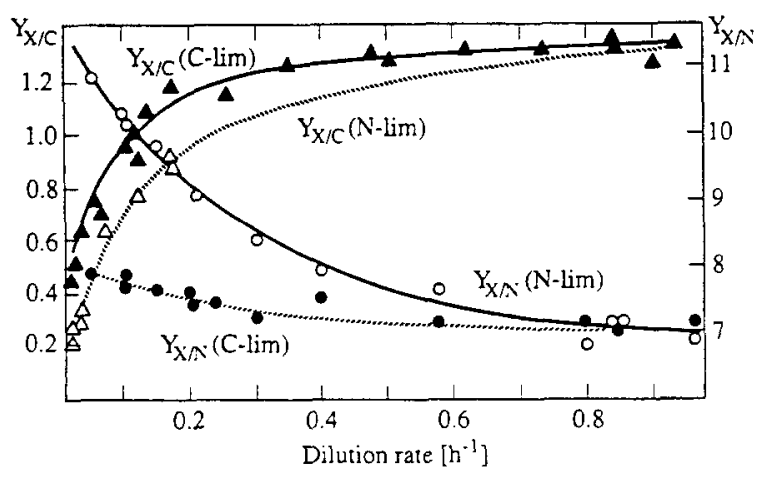

Fig. 3. Growth yield coefficients for carbon $\left(\mathrm{Y}_{\mathrm{X} / \mathrm{C}}\right)$ and nitrogen $\left(\mathrm{Y}_{\mathrm{X} N \mathrm{~N}}\right)$ for a culture of Klebsiella pneumoniae growing in the chemostat either carbon- or nitrogen-limited. Glycerol and $\mathrm{NH}_{4}{ }^{+}$were used as sole sources of carbon and nitrogen, respectively. Each yield coefficient is given in $\mathrm{g}$ dry biomass produced per $\mathrm{g}$ of element. Data from Tempest et al. (1967), Herbert (1976) and Tempest \& Neijssel (1978).

gen-limited grown cells would result in the medium $\mathrm{C}: \mathrm{N}$ ratio where the culture switches from carbon/ nitrogen-limited to nitrogen-limited growth. Applying equation (2) to the growth of Hyphomicrobium ZV620 with methanol and $\mathrm{NH}_{4}{ }^{+}$as carbon and nitrogen sources, the values calculated for the two boundaries (Table 1) correspond closely with those found in the experiment shown in Fig. 1.

Equation (1) implies that in order to obtain a zone of double-substrate-limited growth with substrates $S_{1}$ and $S_{2}$, the growth yield coefficients $Y_{X / S_{1}}$ and/or $Y_{X_{/} S_{2}}$ have to be different under $S_{1}$-limited and $S_{2}$-limited growth conditions, respectively. Additionally, the equation also indicates that the wider the range within which the growth yield coefficients for the two substrates can vary, the more extended the double-substrate-limited growth regime will be. Egli \& Quayle (1986) also predicted that the transition growth regime would become narrower with increasing growth rates because differences in cellular composition and growth yield are markedly more pronounced in slow growing cells (Herbert 1976). This prediction was recently confirmed for a culture of $C$. valida growing at three different dilution rates with ethanol and $\mathrm{NH}_{4}{ }^{+}$as carbon and nitrogen sources (Minkevich et al. 1988).

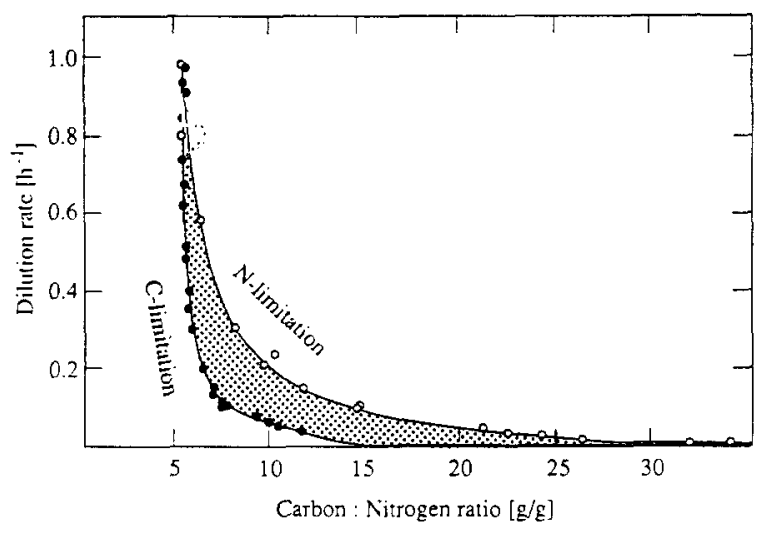

Fig. 4. Dependence of the nature of growth limitation on the carbon: nitrogen ratio of the growth medium supplied and the growth rate for a culture of Klebsiella pneumoniae growing in a chemostat with glycerol and $\mathrm{NH}_{4}{ }^{+}$as the sole sources of carbon and nitrogen.

\section{Applying the concept to literature data}

The simplicity of the method discussed for calculating the different boundaries of growth limitation regimes prompted further examination of the literature. If the growth yield coefficients for two nutrients $S_{1}$ and $S_{2}$ are known for $S_{1}$ - and $S_{2}$-limited growth at different dilution rates in chemostat culture, it would be possible to predict the zone of double $S_{1} / S_{2}$-limited growth for microbes as a function of their growth rates.

One of the best documented examples found in the literature was that for $K$. pneumoniae growing in a synthetic medium with glycerol and ammonia as the only sources of carbon and nitrogen, respectively (Fig. 3). Although the data were derived from different sources (Tempest et al. 1967; Herbert 1976; Tempest \& Neijssel 1978) and, in some cases, required recalculation and transformation, they clearly demonstrate the influence of growth rate and the nature of growth limitation on biomass yield coefficients based on carbon and nitrogen. Data for $\mathrm{Y}_{\mathrm{X} / \mathrm{C}}$ (glycerol) during $\mathrm{NH}_{4}{ }^{+}$-limited growth were scarce, especially at high growth rates and showed considerable scatter. Nevertheless, because at the maximum specific growth rate $\mathrm{Y}_{\mathrm{X} / \mathrm{C}}(\mathrm{N}$ $\lim )$ is theoretically identical to $\mathrm{Y}_{\mathrm{X} / \mathrm{C}}(\mathrm{C}$-lim), the values of $\mathrm{Y}_{\mathrm{X} / \mathrm{C}}$ for nitrogen-limited growth can be interpolated for dilution rates higher than $0.2 \mathrm{~h}^{-1}$. 


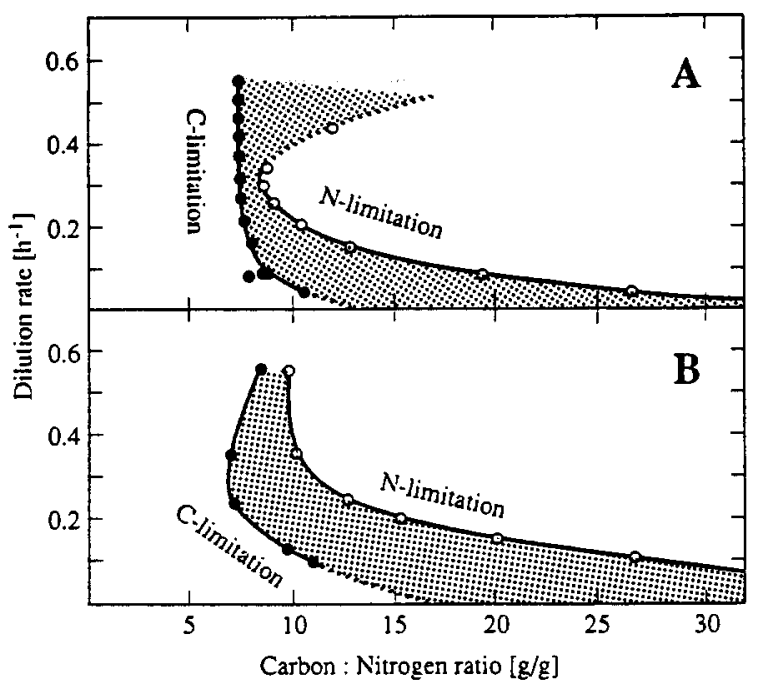

Fig. 5. Dependence of the nature of growth limitation on the carbon : nitrogen ratio of the growth medium supplied and the growth rate for chemostat growth of (A) Candida utilis with glucose and $\mathrm{NH}_{4}^{+}$and (B) Candida valida with ethanol and $\mathrm{NH}_{4}{ }^{+}$. Calculation of boundaries for the growth of C. utilis is based on data from Herbert (1976) and Aiking \& Tempest (1977). Boundaries for $C$. valida are adapted from Minkevich et al. 1988 .

From this set of data $\mathrm{c}_{0} / \mathrm{n}_{0}$ ratios were calculated and the corresponding zone boundaries for growth limitation obtained are shown as a function of growth rate in Fig. 4. As predicted, the extension of the carbon/nitrogen-limited growth regime for a culture of $K$. pneumoniae is strongly dependent on the imposed growth rate.

For example, $\mathrm{D}=0.8 \mathrm{~h}^{-1}$, which is close to the maximum specific growth rate, simultaneous limitation by carbon and nitrogen should be found during growth with media of $\mathrm{C}: \mathrm{N}$ ratios in between 5.4 - 5.6 and would, therefore, be difficult to detect experimentally. However, at $\mathrm{D}=$ $0.05 \mathrm{~h}^{-1}$ double limitation should extend over a much wider range from a $\mathrm{C}: \mathrm{N}$ ratio of 10.6 to 20.6 . The zone of double limitation not only becomes wider with decreasing growth rates but is, at the same time, moved towards higher $\mathrm{C}: \mathrm{N}$ ratios. As a consequence, if the bacterium was grown in a medium with a $\mathrm{C}: \mathrm{N}$ ratio higher than approximately 5.5, growth should become nitrogen-limited at higher dilution rates. With the same medium, the

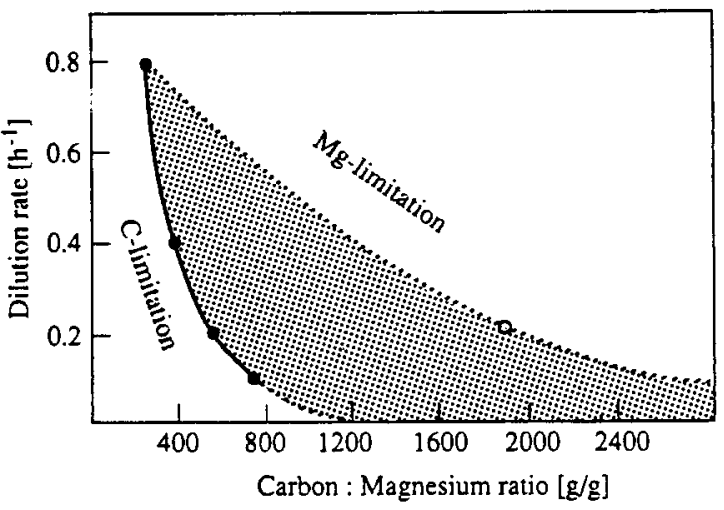

Fig. 6. Predicted dependence of the nature of growth limitation on the carbon : magnesium ratio of the growth medium supplied and the dilution rate for chemostat growth of Klebsiella pneumoniae with glucose and magnesium. Calculation of boundaries is based on data from Strange \& Hunter (1976), Tempest \& Dicks (1967) and Tempest \& Neijssel (1978).

culture would be carbon-limited at growth rates lower than approximately $0.5 \mathrm{~h}^{-1}$.

Similar boundaries for carbon/nitrogen-limited growth of the two yeasts $C$. utilis with glucose/ $\mathrm{NH}_{4}{ }^{+}$and $C$. valida with ethanol/ $\mathrm{NH}_{4}{ }^{+}$(Fig. 5) were calculated from chemostat data reported in the literature (Herbert 1976; Aiking 1977; Minkevich et al. 1988). In the case of $C$. utilis (Fig. 5A) the data reported for growth yield coefficients under nitrogen-limited conditions at dilution rates $>0.3 \mathrm{~h}^{-1}$ were scarce and they suggest that at high growth rates the zone of $\mathrm{C} / \mathrm{N}$-limited growth would become wider again. This could be explained by the extensive excretion of carbonaceous products under such conditions. In contrast, for the growth of $C$. valida with ethanol and ammonia the calculations predicted a zone of double limitation comparable to that for $K$. pneumoniae.

From the evidence presented, it can be envisaged that zones of double-substrate-limited growth will also occur for chemostat growth of microorganisms with substrate combinations other than carbon and nitrogen. Unfortunately, few reliable data were found in the literature on growth yield coefficients at different growth rates for substrate combinations such as, e.g., carbon/magnesium, carbon/phosphorus or carbon/sulfur. Especially data on growth yield coefficients for carbon under carbon excess conditions were rarely reported 


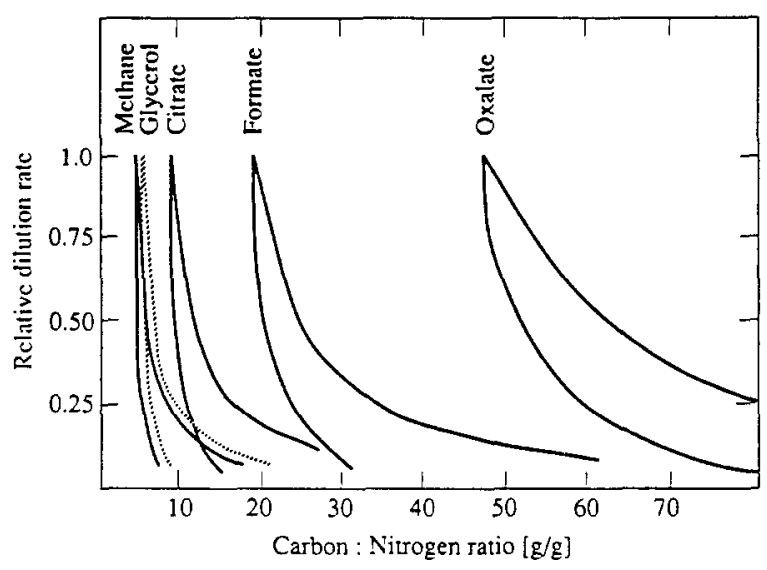

Fig. 7. Influence of growth yield (or degree of reduction of substrates) on the position of boundaries of the double-C/Nlimited growth regime for a hypothetical microorganism. For calculation, maximum growth yield factors were taken from the literature (Linton \& Stephenson 1978) and the same pattern for cell composition and maintenance as shown in Fig. 3 for Klebsiella pneumoniae was applied. Maximum $\mathrm{Y}_{\mathrm{X} / \mathrm{C}}$ values used for calculation were for methane 1.50 , for glycerol 1.35 , for citrate 0.80 , for formate 0.38 and for oxalate 0.15 .

in the literature examined. The best documented example is that of growth of $K$. pneumoniae with glycerol and magnesium under both carbon and magnesium limitation (Strange \& Hunter 1967; Tempest \& Dicks 1967; Tempest \& Neijssel 1982) and the boundaries of the zone for double-(carbon/ magnesium)-limited growth predicted from the data are shown in Fig. 6. Unfortunately, in this example the boundary from carbon/magnesium-limited to magnesium-limited growth conditions is documented at one single dilution rate only and more data are clearly needed. Nevertheless, the emerging outline of the shape of the double-substratelimited zone can be be predicted to be even more extended than that for carbon/nitrogen-limited growth of this bacterium.

\section{Some conclusions and outlook}

With respect to the two nutrients under consideration, one can conclude from the information presented here that the position and shape of the carbon/nitrogen-limited growth regime is mainly influenced by two parameters: growth yield coeffi- cients and the plasticity of cell composition with respect to carbonaceous and nitrogenous cell constituents. Obviously, the influence of growth yield implies that for highly oxidized substrates, i.e., substrates giving low growth yield coefficients (Linton \& Stephenson 1978) this regime will be shifted towards higher $\mathrm{C}: \mathrm{N}$ medium ratios. Furthermore, at low dilution rates endogenous activity (maintenance) together with death/lysis and cryptic growth are the parameters which will determine the shape of the zone of double-nutrient limitation and the shift towards higher medium $\mathrm{C}: \mathrm{N}$ ratios with decreasing growth rates. The effect of growth with substrates of different degrees of reduction is demonstrated in Fig. 7.

The results reported here with respect to the two macro-nutrients, carbon and nitrogen, clearly demonstrate that growth of microbes in continuous culture is frequently not only limited by one single nutrient at any particular time, but can also be limited by two (or more) nutrients simultaneously. The zone of double nutrient limitation is dependent on the $\mathrm{C}: \mathrm{N}$ ratio of the growth medium and the boundaries of the two independent single-substrate-limited growth regimes can be predicted from the growth yield coefficients based on carbon and nitrogen, respectively, measured during single-substrate-limited growth. It is envisaged that the concept of double-nutrient-limited growth presented here for carbon and nitrogen can be extended to other combinations of nutrients. Cells growing within such double-nutrient-limited zones are characterized by a potentially variable cell composition with respect to both the structural components and the enzymes expressed, which results in increased metabolic flexibility and versatility. The data reported by Wanner \& Egli (1990) on the patterns of growth and changes of cellular composition of $K$. pneumoniae during limitation by different nutrients in batch culture suggests that extensively extended zones of double-substrate-limited growth for nutrient combinations such as carbon/ phosphorus and carbon/potassium can be expected at low growth rates.

From the data presented it can be assumed that microbial growth in the chemostat can be limited by more than two nutrients simultaneously. As an 


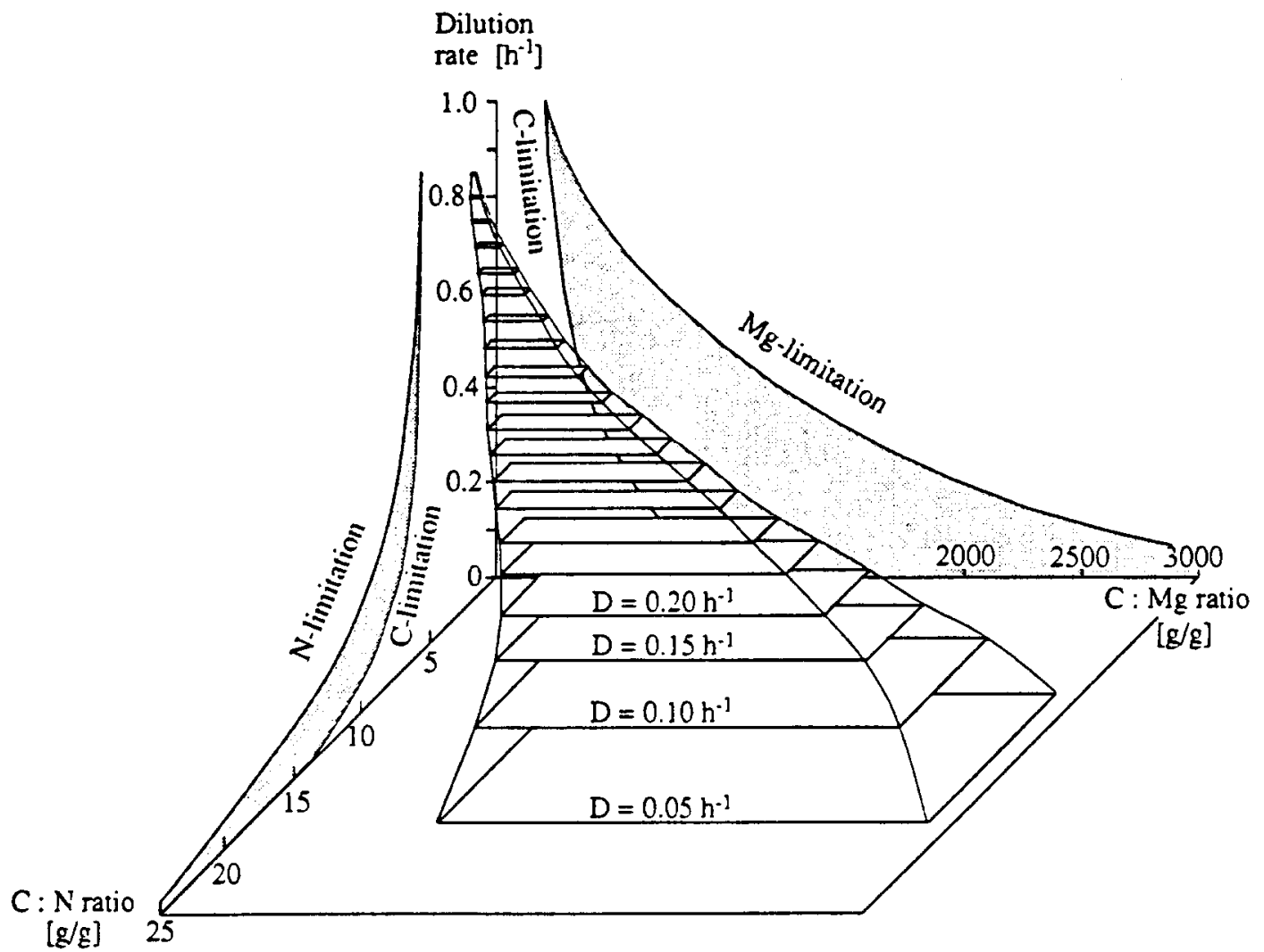

Fig. 8. Predicted zone of triple nutrient (carbon, nitrogen and magnesium) limitation for growth of Klebsiella pneumoniae in chemostat culture, as a function of dilution rate. Calculation of boundaries is based on data from Strange \& Hunter (1967), Tempest \& Dicks (1967) and Tempest \& Neijssel (1978).

example, the theoretical position of the zone of triple-substrate-limited growth by carbon, nitrogen and magnesium at different dilution rates has been calculated for $K$. aerogenes from literature data (Fig. 8). The data clearly predict an extended zone of simultaneous limitation by the three nutrients at low growth rates.

The concept presented here on double-substrate-limited growth allows several conclusions to be drawn concerning growth of microorganisms under both laboratory and environmental conditions. First, with respect to growth with carbon and nitrogen sources, one can predict that studies on nitrogen-limited growth at low growth rates may require rather higher ratios of $\mathrm{C}: \mathrm{N}$ in the medium than are commonly used, i.e., the lower the dilution rate, the higher the medium $\mathrm{C}: \mathrm{N}$ ratio needed to ensure distinctly nitrogen-limited growth conditions. Additionally, it can be concluded that tests to confirm that growth is carbon-limited should be performed at high dilution rates, whereas low dilution rates should be employed when testing for nitrogen limitation. Also, the fact that in the example presented in Fig. 1A the dry weight in the culture still increased linearly in the carbon/nitrogen-limited zone indicates that the traditional procedure of assessing the limiting factor in a growth medium via the amount of biomass produced can lead to ambiguous results.

From a microbial ecologist's viewpoint, the shape of the limitation zones in Fig. 4 indicate the crucial importance of the growth yield coefficient on the regime of growth limitation under natural environmental conditions. Considering that growth rates of bacteria in ecosystems are low, i.e., frequently in the range of $0.001-0.01 \mathrm{~h}^{-1}$, for extended periods of time (Moriarty 1986), then in the case of the two macro-nutrients carbon and nitro- 
gen, environmental $\mathrm{C}: \mathrm{N}$ ratios have to be rather high before microbial growth becomes fully nitrogen-limited.

With respect to wastewater treatment, the existence of a double-substrate-limited zone provokes the speculation that simultaneous removal of, e.g., carbonaceous and nitrogenous compounds in the double-limited zone should be possible. Such an application can be envisaged for the treatment of industrial wastewaters where it is occasionally possible to adjust the ratio of different nutrients by mixing wastewaters from different processes.

Although the concept of double nutrient limitation still needs further examination, it is hoped that this contribution will add a shade of grey to our black and white thinking concerning the nutrientlimited growth of microbes.

\section{Acknowledgements}

The author is indepted to G. Hamer for his continued interest in this work and the many stimulating discussions, to C.A. Mason for his help during the preparation of the manuscript and to $\mathrm{H}$. Bolliger for drawing the figures. A preliminary version of this article was published recently (Egli \& Schmidt 1990).

\section{References}

Aiking H \& Tempest DW (1977) Rubidium as a probe for function and transport of potassium in the yeast Candida utilis NCYC 321, grown in chemostat culture. Arch. Microbiol. 115: 215-221

Al-Awadhi N, Egli T, Hamer G \& Mason CA (1990) The process utility of thermotolerant methylotrophic bacteria: $\mathrm{I}$. An evaluation in chemostat culture. Biotechnol. Bioeng. 36: $816-820$

Baltzis BC \& Fredrickson AG (1988) Limitation of growth rate by two complementary nutrients: some elementary but neglected considerations. Biotechnol. Bioeng. 31: 75-86

Cooney C, Wang DIC \& Mateles RI (1976) Growth of Enterobacter aerogenes in a chemostat with double nutrient limitations. Appl. Environ. Microbiol. 31: 91-98

Duchars MG \& Attwood MM (1989) The influence of the carbon: nitrogen ratio of the growth medium on the cellular composition and regulation of enzyme activity in Hyphomicrobioum X. J. Gen. Microbiol. 135: 787-793

Egli T (1982) Regulation of protein synthesis in methylotrophic yeasts: repression of methanol dissimilating enzymes by nitrogen limitation. Arch. Microbiol. 131: 95-101

Egli T \& Quayle JR (1984) Influence of the carbon : nitrogen ratio on the utilization of mixed carbon substrates by the methylotrophic yeast Hansenula polymorpha. Proceedings of the 100th Annual Meeting of the Society for General Microbiology, Warwick (p M13)

- (1986) Influence of the carbon : nitrogen ratio of the growth medium on the cellular composition and the ability of the methylotrophic yeast Hansenula polymorpha to utilize mixed carbon sources. J. Gen. Microbiol. 132: 1779-1788

Egli T \& Schmidt CR (1990) Dual-nutrient-limited growth of microbes, with special reference to carbon and nitrogen substrates. In: Hamer G, Egli T \& Snozzi M (Eds) Mixed and Multiple Substrates and Feedstocks (pp 165-167). HartungGorre, Constance

Egli, T, Bosshard C \& Hamer G (1986) Simultaneous utilization of methanol-glucose mixtures by Hansenula polymorpha in chemostat: influence of dilution rate and mixture composition on utilization pattern. Biotechnol. Bioeng. 28: 1735-1741

Gräzer-Lampert SD, Egli T \& Hamer G (1986) Growth of Hyphomicrobium ZV620 in the chemostat: regulation of $\mathrm{NH}_{4}{ }^{+}$-assimilating enzymes and cellular composition. J. Gen. Microbiol. 132: 3337-3347

Hamer G, Harrison DEF, Harwood JH, Topiwala HH (1975) SCP production from methane. In: Tannenbaum SR \& Wang DI (Eds) Single Cell Protein II (pp 357-369). MIT Press, Cambridge, Mass.

Harder W \& Dijkhuizen L (1976) Mixed substrate utilization. In: Dean ACR, Ellwood DC, Evans GGT, Melling J (Eds) Continuous Culture 6: Applications and New Fields (pp 297314). Ellis Horwood, Chichester

- (1982) Strategies of mixed substrate utilization in microorganisms. Phil. Trans. R. Soc. Lond. B 297: 459-480

Harrison DEF (1972) Physiological effects of dissolved oxygen tension and redox potential on growing populations of microorganisms. J. Appl. Chem. Biotechnol. 22: 417-440

Herbert D (1976) Stoicheiometric aspects of microbial growth. In: Dean ACR, Ellwood DC, Evans CGT \& Melling J (Eds) Continuous Culture 6: Applications and New Fields (pp 130). Ellis Horwood, Chichester

Hueting S \& Tempest DW (1979) Influence of the glucose input concentration on the kinetics of metabolite production by Klebsiella aerogenes NCTC 418: growing in chemostat culture in potassium- or ammonia-limited environments. Arch. Microbiol. 123: 189-199

von Liebig J (1840) Organic Chemistry in its Application to Agriculture and Physiology [English translation by L. Playfair]. Taylor and Walton, London

Linton JD \& Stephenson RJ (1978) A preliminary study on growth-yields in relation to the carbon and energy-content of 
various organic growth substrates. FEMS Microbiol. Lett. 3 : 95-98

Minkevich IG, Krynitskaya AY \& Eroshin VK (1988) A double substrate limitation zone of continuous microbial growth. In: Kyslik P, Dawes EA, Krumphanzl V \& Novak M (Eds) Continuous Culture (pp 171-189). Academic Press, London

Monod J (1942) La croissance des cultures bactériennes. Hermann, Paris

Moriarty DJW (1986) Measurement of bacterial growth rates in aquatic systems from rates of nucleic acid synthesis. Adv. Microb. Ecol. 9: 245-292

Pearl HP (1977) Factors limiting productivity of freshwater ecosystems. Adv. Microb. Ecol. 6: 75-110

Robertson LA \& Kuenen JG (1990) Mixed terminal electron acceptors (oxygen and nitrate). In: Hamer G, Egli T \& Snozzi M (Eds) Mixed and Multiple Substrates and Feedstocks (pp 97-106). Hartung-Gorre, Constance

Rutgers M, Balk PA \& van Dam K (1990). Quantification of multiple-substrate controlled growth. Simultaneous ammonium and glucose limitation in chemostat cultures of Klebsiella pneumoniae. Arch. Microbiol. 153: 478-484

Stephenson M (1949) Growth and nutrition. In: Bacterial Metabolism, 3rd ed (pp 159-178). Longmans, Green \& Co., London
Strange RE \& Hunter JR (1967) Effect of magnesium on the survival of bacteria in aqueous suspension. In: Powell EO, Evans CGT, Strange RE \& Tempest DW (Eds) Microbial Physiology and Continuous Culture (pp 102-123). H.M.S.O., London

Tempest DW, Herbert D \& Philipps PJ (1967) Studies on the growth of Aerobacter aerogenes at low dilution rates in a chemostat. In: Powell EO, Evans CGT, Strange RE \& Tempest DW (Eds) Microbial Physiology and Continuous Culture (pp 240-257). H.M.S.O., London

Tempest DW \& Dicks JW (1967) Interrelationships between potassium, magnesium, phosphorus and ribonucleic acid in the growth of Aerobacter aerogenes in a chemostat. In: Powell EO, Evans CGT, Strange RE \& Tempest DW (Eds) Microbial Physiology and Continuous Culture (pp 140-145). H.M.S.O., London

Tempest DW \& Neijssel OM (1978) Eco-physiological aspects of microbial growth in aerobic nutrient-limited environments. Adv. Microb. Ecol. 2: 105-153

Veldkamp H \& Jannasch HW (1972) Mixed culture studies with the chemostat. J. App. Chem. Biotechnol. 22: 105-123

Wanner U \& Egli T (1990) Dynamics of microbial growth and cell composition in batch culture. FEMS Microbiol. Rev. 75: 19-44 